\title{
Adopting XBRL in Italy: \\ Early evidence of fit between Italian GAAP \\ Taxonomy and current reporting practices of non-listed companies
}

Diego Valentinetti. University "G. d'Annunzio" of Chieti-Pescara. Italy. d.valentinetti@unich.it

Michele A. Rea. University "G. d'Annunzio" of Chieti-Pescara. Italy. m.rea@unich.it

\begin{abstract}
XBRL (eXtensible Business Reporting Language) will soon be the leading means of corporate financial reporting. A key feature of its adoption relies on well-defined standard taxonomies, which should adequately reflect both the accounting standards and the reporting practices of firms. This study considers this issue, following the concept of "taxonomy fit" proposed by Bovee et al. (2002; 2005) and Bonsón et al. (2009a). The aim is to fill a specific gap in the previous literature, by analyzing the applicability of XBRL in the context of template-based accounting standards. Specifically, we assess the fit between the XBRL Italian GAAP Taxonomy and the traditional annual reports of Italian non-listed companies, which are required to file their financial statements in XBRL. The results show an almost perfect fit but with significant differences among the financial statements analyzed. In addition, the degree of misfit, when it occurs, depends on the sector, the size and the level of disaggregation of information provided by the companies.
\end{abstract}

Keywords: XBRL, XBRL taxonomy, financial reporting, XBRL adoption in Italy

\section{INTRODUCTION}

XBRL (eXtensible Business Reporting Language) is increasingly being used around the world. Currently, its benefits for business communication in terms of better, cheaper and faster sharing of data are well known (Bonsón et al. 2009b). Recent studies describe how XBRL can support more effective analysis processes 
and business reporting (Ghani et al. 2009; Marshall et al. 2010) and how it can affect users' perceptions and preferred reporting formats (Ghani et al. 2009). Furthermore, an up-to-date analysis of the XBRL literature reveals a steady interest in both the academic and practitioner contexts (Roohani et al. 2010).

At the first stage of its development, XBRL focuses on external financial reporting, and more specifically, on financial statements of firms. This requires a special effort in developing a set of standard elements to represent each item in financial reports (Debreceny and Gray 2001). According to Bovee et al. (2002), a financial reporting taxonomy can be defined as "a chart of accounts with agreedupon meanings, together with specified relations between the accounts". Additionally, more elements can be added to the taxonomies thanks to the extensibility of the language. In this sense, the extent of information that is retrievable from XBRL instance documents depends on the taxonomies used for tagging the data. Hence, it is necessary to assess the compliance of taxonomies both with accounting standards and with the financial reporting practices of firms.

This study considers the fit between XBRL standard taxonomies and accounting concepts of financial statements (Bovee et al. 2002; Bovee et al. 2005; Bonsón et al. 2009a). The aim is to fill a specific gap in the previous literature by analyzing the applicability of XBRL in the context of template-based standards. In particular, we assessed the fit between the XBRL Italian GAAP Taxonomy released in December 2008 and the traditional annual PDF reports of Italian non-listed companies, which are required to file their financial statements in XBRL as of 2009. The results show an almost perfect fit between the taxonomy and the financial items retrieved in Balance Sheets and Income Statements, while there is a considerable degree of misfit in Memorandum Accounts. In addition, the degree of misfit, when it occurs, depends on the sector, the size and the level of disaggregation of information provided by the companies.

The remainder of this paper is structured as follows. Section 2 focuses on XBRL taxonomies, which represent the framework of this study, and outlines the adoption of XBRL in Italy. Section 3 explains the research methods and the results obtained. Section 4 discusses the results and suggests some implications for future research studies. 


\section{BACKGROUND}

\subsection{Literature review of XBRL taxonomies}

XBRL (eXtensible Business Reporting Language) is a computer meta-language for business reporting by firms. It aims to improve the communication of financial and business information, allowing a seamless flow of data across computers and thus facilitating the sharing of data by the users. Based on XML (eXtensible Markup Language), it allows computer applications to identify the data through a system of "tagging", that is, the process of assigning XBRL "tags" to financial data. The tags are computer readable and can be processed by the software for a variety of purposes using some XML-based standards that support the language ${ }^{1}$.

The most important standard is the XSD (XML Schema Definition), which allows the definition of the structure of XML documents. Specifically, it defines which elements can appear, the hierarchical order of the elements and their attributes, such as data type, default values and fix values, period type, etc. XLink (XML Linking Language) defines the relationships among the concepts and the relationship between those concepts and other external resources by using "linkbases". Currently, XBRL uses the following linkbases: definition linkbases describe logical relationships between concepts, calculation linkbases define how elements are calculated, presentation linkbases define the relationships between the ways in which the concepts are ordered or nested, label linkbases provide human readable names in different languages for each element, and reference linkbases refer to external authoritative literature (such as laws or financial accounting practices). The XBRL elements used for tagging the data are structured into taxonomies, whereas the business facts, once tagged, are reported in XBRL instance documents. A similar structure leads us to consider the relevant role of taxonomies that allow the codification of data in the XBRL format. The taxonomy tags "focus on representing data from traditional financial statements" (Marshall et al. 2010) and represent "the best substratum for expressing business information of all kinds for utilization by the numerous applications that companies and other organizations must use to manage this information" (Bonsón

\footnotetext{
${ }^{1}$ See http://www.w3c.org
} 
et al. 2009c). In other words, the extent of information retrievable from XBRL instance documents depends on the taxonomies used for tagging the data. Additionally, companies can extend the standard taxonomies by using new tags "to present their own information and tell their own story, as opposed to having data aggregators tell the story of them" (XBRL US 2010). Hence, the XBRL taxonomies are necessarily the core element in the future digital financial reporting of firms.

A considerable strand of the XBRL literature examines this issue, addressing several interesting research questions. According to Locke and Lowe (2007), the acceptance of taxonomies is a relevant challenge for the successful development and diffusion of XBRL. Debreceny et al. (2005) discuss a series of research implications of the development of XBRL taxonomies; specifically, they focus on the completeness of taxonomies, the factors that determine the adequacy of standard taxonomies and the role of extensions in the standard taxonomies. Baldwin et al. (2006) outline the potential impacts of XBRL on the quality of financial information in terms of a series of relevant characteristics ${ }^{2}$ : consistency and comparability, reliability and accessibility, relevance, decision usefulness and transparency. They argue that XBRL may improve the quality of financial information by virtue of well-defined standard taxonomies and a radical increase in the degree of automation facilitated by those taxonomies. Other studies (Boritz and No 2003; Cohen et al. 2003; Lymer and Debreceny 2003; Boritz and No 2008; Plumlee and Plumlee 2008; Boritz and No 2009; Srivastava and Kogan 2009) consider the role of taxonomies for assurance on XBRL financial reporting, addressing the problem of data quality. In particular, Srivastava and Kogan (2009) develop a conceptual framework of assertions for providing assurance on XBRL instance documents. Four of these concern the taxonomies: the choice of appropriate XBRL taxonomies for drawing instance documents ("Proper Taxonomies"), the compliance of taxonomy extensions with all XML and XBRL rules ("Valid Taxonomy Extensions"), the appropriate introduction of new elements in XBRL taxonomy extensions ("Proper Extension Elements") and the

\footnotetext{
2 These characteristics are identified by FASB (1980): Quality Characteristics of Accounting Information. Statement of Financial Accounting Concepts No. 2. Financial Accounting Standard Board, Stamford.
} 
appropriateness of linkbases in XBRL taxonomy extensions ("Proper Linkbases"). Along the same lines, Debreceny et al. (2010) state that the design and complexity of taxonomies may affect the data quality of instance documents.

A key feature of XBRL development for financial reporting is the standardization of financial information. According to Chang and Jarvenpaa (2005), "XBRL is expected to become the global data standard for financial statement information over the Internet". Similarly, Wagenhofer (2003) argues that the widespread adoption of XBRL will standardize both the format and the content of financial information. This is undoubtedly a very important issue for financial reporting and, more broadly, for accounting matters, in view of the global adoption of International Financial Reporting Standards. Similar considerations lead us to consider two interrelated aspects.

On one hand, the process of "translating" accounting standards into XBRL is a very relevant challenge; this task requires the development of well-structured taxonomies that accommodate existing reporting standards. In this context, many authors highlight the role of XBRL taxonomies in the standardization of financial reporting. In particular, Bonsón (2001) analyzes the role of XBRL in the European Union, combined with the adoption of the International Financial Reporting Standards (IFRS); he describes the advantage of having a unique framework for financial reporting: this allows us to define a standard XBRL taxonomy, including a unique set of element names and a different set of element labels for each language. It also allows us to use the alternative accounting valuation methods granted by the IFRS. Bonsón et al. (2009a) state that the IFRS-GP Taxonomy, which is itself based on IFRS, constitutes a common platform for the use of XBRL. Similarly, Efendi et al. (2009) argue that XBRL, in conjunction with IFRS, could have a positive effect on accounting and financial reporting worldwide. Moreover, XBRL usage could encourage firms to report under a single GAAP worldwide (Wagenhofer 2003). Hence, we can state that a strong relationship between XBRL taxonomies and the accounting standards is required. This task primarily involves the standard setters, which have to "convert" the accounting rules that they issue into a comprehensive set of XBRL tags (i.e., into standard taxonomies). 
On the other hand, the diffusion of XBRL in financial reporting cannot ignore the reporting needs of firms; these firms are the first users of XBRL because they have to tag each concept of their financial accounts. Therefore, the taxonomies should be able to accommodate financial reporting practices to meet user demands at the country, industry or firm level (Debreceny and Gray 2001; Bovee et al. 2005; Debreceny et al. 2005; Baldwin et al. 2006).

In the academic literature, two main empirical studies consider these two aspects in conjunction: the concept of "fit" between XBRL taxonomies and financial reporting concepts; the aim is to investigate whether a standard XBRL taxonomy adequately reflects the financial reporting practices of firms. Bovee et al. (2002) assessed the year 2000 version of the XBRL taxonomy for financial reporting by commercial and industrial $(\mathrm{C} \& \mathrm{I})$ firms under U.S. GAAP. The results show a good fit overall, even though some of the significant differences observed across financial statements and industries suggest the need to develop industry-specific extensions to the taxonomy. A similar study was conducted by Bonsón et al. (2009a) with the aim of detecting whether the IFRS-GP Taxonomy adequately covers European companies' reporting practices. Their findings show that the account items disclosed by the sample companies are largely covered by the Taxonomy; among the divergences that occurred, however, a higher degree of misfit was observed for the financial and insurance sector and for Statements of Changes in Equity, which confirms that this degree depends on the sector of the firms and the type of financial statement. However, these studies focus on principle-based standards, which offer guidelines and then allow a certain flexibility in the presentation of financial statements. The analysis of the level of misfit between financial reporting practices and the taxonomies can be understood as a suggestion for the further evolution of the taxonomies. However, to date, there is a lack of studies of template-based standards. Therefore, the possible misfits can indicate not only a possible evolution of the taxonomies but also a call for compliance with the standards by the accounting managers. In this context, the Italian case is very convenient because the mandatory filing of annual reports in XBRL is organized according to a XBRL taxonomy that reflects a set of templatebased accounting requirements. For this reason, before presenting our research question, we provide a brief outline of the adoption of XBRL in Italy. 


\subsection{XBRL adoption in Italy}

In recent years, XBRL has attracted widespread interest in Italy owing to the cooperation of several entities in the financial community. In September 2006, the "XBRL Italy" Association was established with the aim of supporting the standardization and modernization of financial communication; subsequently, in May 2007 the association obtained the status of Italian jurisdiction from the XBRL International Consortium ${ }^{3}$. Several working groups were set up within the organization; among these, a specific task force designed the first XBRL taxonomy based on Italian GAAP for limited companies that do not apply the International Financial Reporting Standards (IFRS). Using that taxonomy and an ad hoc tool, a voluntary filing of financial statements in XBRL format was promoted by the Italian Business Register of Firms in May 2006. The testing has been useful for at least two reasons. First, it allowed them to identify the common errors retrieved in each instance document, providing important feedback on the accuracy of tagged data ${ }^{4}$. Second, participants had a great opportunity to familiarize themselves with XBRL in view of the imminent compulsory filing of financial statements in XBRL format.

At the same time, a legislative bill (Law No. 248 of August 4, 2006) proposed the adoption of XBRL for most mandatory filings of firms. Finally, a Prime Ministerial Decree issued on December 10, 2008, provided for the compulsory filing of financial statements in XBRL format for the limited companies that do not apply the International Financial Reporting Standards (IFRS). Banking and insurance companies are not involved. Specifically, the rule applies to financial statements drawn according to the Italian accounting principles based on Civil Code requirements ${ }^{5}$. Three documents are involved: the Balance Sheet, the Income Statement and the Memorandum Accounts ${ }^{6}$. For this purpose, a standard

\footnotetext{
${ }^{3}$ See http://www.xbrl.org/it/

${ }^{4}$ The numbers of XBRL instance documents voluntarily filed by the firms have increased over the years: 34 instance documents in 2006, 905 instance documents in 2007 and more than 9000 instance documents in 2008.

${ }^{5}$ The number of companies involved in mandatory filing is more than 900.000 .

${ }^{6}$ The Memorandum Accounts chart is a particular document (not compulsory) to be disclosed at the foot of the Balance Sheet. It shows the so called "minor accounts," such as guarantees granted, commitments, risks, etc.
} 
taxonomy ${ }^{7}$ was officially released on February 16, 2009; thus, the first application of XBRL mandatory filing included the ongoing financial year from December 31, 2008 and closed after February 16, 2009.

\subsection{Research question and hypotheses}

This survey aims to assess the fit between the traditional annual reports of Italian non-listed companies and the Italian GAAP Taxonomy released for XBRL mandatory filing in Italy. This Taxonomy reflects the annual accounts layout established by the Italian Civil Code $^{8}$ for non-listed limited companies, which means that the annual account regulations provide a rigid schema for the content of the financial statements. Specifically, art. 2424 and 2425 provide, respectively, a mandatory hierarchical structure for the accounting items of Balance Sheet and Income Statement ${ }^{9}$. However, the article 2423ter grants some derogations of the mandatory outlines under certain conditions: a) the subdivision of the items, without the elimination of the comprehensive amount; b) the grouping of the items, when their amounts are insignificant for the "clarity" and "true and fair view" principles; and c) the addition of new items, when certain information cannot be included in the provided items. These options allow a "flexible zone" for corporate managers preparing the mandatory annual reports; for that reason, these discretionary elements are not included in the taxonomy. In light of this situation, our purpose is to investigate the fit between the taxonomy and the reporting practices of the companies to examine the extent to which they satisfy the reporting requirements. The research question is as follows:

RQ: To what extent are Italian non-listed companies satisfying the reporting requirements expressed by the Italian GAAP Taxonomy?

This is a very relevant question because the degree of fit allows us to assess how the companies are applying the reporting requirements. Specifically, it is possible to identify the extent to which the firms use the flexible zone granted by the Italian regulation. In this case, two particular situations can occur. On one

\footnotetext{
${ }^{7}$ See http://www.xbrl.org/it/nmpxbrl.aspx $? \mathrm{id}=271$

${ }^{8}$ The Italian Civil Code provides the regulations for the annual accounts of limited companies in a specific section, entitled "On annual accounts", from article 2423 to article 2435 bis.

${ }^{9}$ The art. 2424, related to the Balance Sheet, also provides the content of Memorandum Accounts.
} 
hand, the subdivision of the items and the addition of new items represent a situation in which the firms prefer to report more disaggregated information than the core schema provided by the regulation and the Taxonomy. On the other hand, the grouping of items represents a situation in which the firms prefer to report less disaggregated information than the core schema. This paper aims to consider these possible situations and to analyze the behavior of companies in applying the taxonomy. The practices of subdivision and addition of new items, in fact, can justify the definition of some private extensions because certain companies need to report financial information in a more disaggregated form than the rigid schema of the taxonomy. The grouping of the items can represent a loss of information identified by the Taxonomy. Reasonably, both of the situations depend on the particular characteristics of the companies, which can affect the level of disaggregation of the information provided. The goal is also to ascertain empirically which factors can explain the difference between the levels of disaggregation. For this purpose, the following hypotheses have been stated on the basis of the most relevant explanatory factors identified in the previous literature.

Several studies reveal that the industry sector affects the amount of information provided by companies (Armenic and Maiocco 1981; Bazley et al. 1985; Bonsón and Escobar 2002; Bonsón and Escobar 2006). A relevant reason is that companies belonging to the same sector need to acquire legitimacy and a particular corporate image from their specific environment, so they prefer to adopt similar reporting practices. This leads to the first hypothesis:

$\mathbf{H}_{\mathbf{1}}$ : The level of disaggregation of the financial information provided by companies depends on their sectors.

Fourteen dichotomous variables have been created to represent the different industrial sectors according to the "Industry Classification Benchmark" (ICB) system $^{10}$.

The size of the company is another relevant variable that is widely studied in the accounting literature as an explanatory factor for the extent of financial

10 The Industry Classification Benchmark is a single standard defining the industry classification system actually adopted by the FTSE and Dow Jones Indexes. See http://www.icbenchmark.com/index.html 
disclosure (Chow and Wong-Boren 1987; Lang and Lundholm 1993; Mckinnon and Dalimunthe 1993; Aitken et al. 1997; Adams and Hossain 1998; Craven and Marston 1999; Craven and Otsmani 1999). The positive relationship seems to be justified by the low costs sustained by the larger companies for preparing and disclosing voluntary information. Furthermore, the largest companies have to satisfy a higher number of stakeholders, who require more information. This leads to the second hypothesis:

$\mathbf{H}_{2}$ : The level of disaggregation of the financial information provided by companies depends on their size.

The value of the logarithm of the total assets has been considered as a proxy for company size.

According to the relevant accounting literature, the type of audit can also affect the disclosure practices of the firms. Specifically, the common subdivision of auditing firms into the Big $4^{11}$ and the non-Big 4 seems to be relevant based on several studies (Wallace et al. 1994; Wallace and Naser 1995; Camfferman and Cooke 2002). This leads to the third hypothesis:

$\mathbf{H}_{3}$ : The level of disaggregation of the financial information provided by companies depends on the type of audit.

A dichotomous variable has been created to identify which companies were audited by one of the Big 4 .

Lastly, we aim to investigate in depth the level of disaggregation of the information, simultaneously considering the dichotomy "subdivision and addition of new items - grouping of items" explained in our framework. In other words, we ask whether the tendency to provide more disaggregated information for some items is negatively associated with the tendency to provide less disaggregated information for other items. This leads to the fourth hypothesis:

$\mathbf{H}_{4}$ : Companies providing information that is more disaggregated than the taxonomy for certain items are prone to avoiding the disclosure of less

\footnotetext{
11 The so-called "Big 4" audit companies are Deloitte, PricewaterhouseCoopers, Ernst \& Young and KPMG.
} 
disaggregated information for other items in the same report.

The variables created for the evaluation of the hypotheses will be presented in the next section.

\section{RESEARCH METHOD AND RESULTS}

To assess the fit between the XBRL Italian GAAP Taxonomy and the traditional annual reports of Italian non-listed companies, we extended the procedure employed by Bovee et al. $(2002 ; 2005)$ and later by Bonsón et al. (2009a). Specifically, we compared each line item of the financial statements analyzed, in PDF format, with the XBRL elements of the taxonomy; this procedure aims to determine, for each financial concept reported in the financial statements, the appropriate XBRL tag that could be assigned. In this way, it is possible to verify, as a first step, the goodness of the fit between the taxonomy and the reporting practices of the companies. The deviations that occurred were collected as Elements for Special Attention (ESA); this variable indicates the number of financial statement elements without a direct counterpart in the taxonomy. A positive value indicates the absolute number of misfits noticed, whereas a value of zero indicates a perfect fit (no misfit noticed). To obtain a proportion, the variable ESA was divided by the total number of line items comprising each financial statement ${ }^{12}$. The new variable obtained (PROP) indicates the degree of misfit between the taxonomy and the financial statements analyzed.

The following step of the study was to analyze the misfits observed to investigate the nature of each misfit. For this purpose, based on Bovee et al. (2002), we catalogued the ESA collected into three groups:

- Firm Specific, which are idiosyncratic financial statement items containing firm or industry specific detail;

- Grouped, which are the financial statement items that map to several taxonomy tags;

\footnotetext{
12 This means that the denominator of the calculation is not a constant because it depends on the number of line items that comprise the financial statements of each company analyzed.
} 
- New Tags, which are the financial statement items retrieved by a significant number of companies that do not have a corresponding taxonomy tag.

It is evident that the first and the third classes of ESA (Firm Specific and New $\mathrm{Tag}$ ) indicate the number of items that are more disaggregated than the taxonomy tags; the second class (Grouped) indicates the number of items that are less disaggregated than the taxonomy tags. On the basis of this framework, we have created a new variable to evaluate the level of disaggregation of the information provided by the companies when compared with the Italian GAAP Taxonomy:

$$
\text { DIS }_{\mathrm{PROP}}=\frac{\text { Firm Specific }+ \text { New Tags }}{\text { total items }}
$$

where Dis_PROP stands for "Disaggregated PROP". This variable indicates the additional information that can be retrieved from the financial statements because of the reporting details provided by the companies. For the same reason, the Grouped items were transformed and renamed as Constr_PROP to identify the proportion of accounting items that were less disaggregated ("constricted") than the taxonomy schema. Both of these variables will be used to estimate empirically which factors can affect the level of disaggregation of the reporting practices of the Italian non-listed companies.

\subsection{Sampling and tagging process}

The analysis was conducted on a random sample of Italian non-listed companies registered at the Italian Business Register of Firms. We selected an optimum sample of 268 companies (confidence level of $90 \%$ and maximum admissible error of 5\%) that compile their financial statements according to the Italian Civil Law GAAP ${ }^{13}$. From the original sample, we deleted 4 companies that were in winding-up, obtaining a final sample of 264 companies. Then we retrieved, for each company in the sample, the three main documents of the financial statements produced at the end of the year 2008: the Balance Sheet, the

\footnotetext{
${ }^{13}$ In this analysis, we did not consider three categories of accounts provided for Italian financial reporting regulation: abridged annual accounts, simplified annual accounts and consolidated annual accounts. For these accounts, in fact, specific tags are provided in the Taxonomy.
} 
Income Statement and the Memorandum Accounts. The documents were extracted from a database ${ }^{14}$ comprising the financial statements (in PDF format) officially filed by the companies and submitted to the Italian Registry of Business Enterprises; in this way, we preserved the original formatting of each financial statement.

The tagging process followed a keynote rule: it was based on the meaning rather than the word form of each financial account disclosed, so we did not consider abbreviations of accounts or the absence of alpha-numerical codification of the items as ESA. Rather, we considered all of the items related to the hierarchical structure of each financial statement (macro-classes, classes, items, sub-items), including all of the headings and totals disclosed. Any items with amounts equal to zero were not considered, unless they had a value other than zero in the previous year ${ }^{15}$. The tagging process was performed by only one person to provide a high degree of consistency.

\subsection{Results}

As a first overview, Table 1 shows the descriptive statistics of the ESA and PROP per firm. Both variables have a positive value, indicating the presence of misfit. In particular, the mean value of PROP per firm (4.84\%) indicates a very good fit between the taxonomy and the financial accounts of firms. Furthermore, if we consider the PROP per financial statements (Table 2), we notice an almost perfect fit for Balance Sheet and Income Statement (only $4.12 \%$ and 3.85\% misfit, respectively), whereas the Memorandum Accounts have a consistent degree of misfit $(32.52 \%)$.

\begin{tabular}{|l|r|r|r|r|r|}
\cline { 2 - 6 } \multicolumn{1}{c|}{} & \multicolumn{1}{c|}{$\mathrm{N}$} & \multicolumn{1}{c|}{ Mean } & Std. Deviation & \multicolumn{1}{c|}{ Minimum } & \multicolumn{1}{c|}{ Maximum } \\
\hline ESA per Firm & 264 & 7.19 & 14.943 & 0 & 141 \\
PROP per Firm & 264 & 0.04842 & 0.077859 & 0.000 & 0.530 \\
\hline
\end{tabular}

Table 1: Descriptive Statistics of ESA and PROP per Firm

\footnotetext{
${ }^{14}$ The database is AIDA - Bureau van Dijk. See http://www.bvdep.com/it/AIDA.html

${ }^{15}$ During the tagging process, in fact, we noticed that some companies prefer to disclose only the items with values other than zero, whereas others prefer also to disclose the items with amounts equal to zero. Because the denominator of PROP is represented by the total number of items in each financial statement, we decided to consider only the items with values other than zero, in order to maintain consistency in the calculation of PROP.
} 


\begin{tabular}{|l|r|r|r|r|r|}
\cline { 2 - 6 } \multicolumn{1}{c|}{} & \multicolumn{1}{c|}{$\mathrm{N}$} & Mean & Std. Deviation & Minimum & Maximum \\
\hline PROP per BS & 264 & 0.04124 & 0.071658 & 0.000 & 0.451 \\
PROP per IS & 264 & 0.03853 & 0.093189 & 0.000 & 0.636 \\
PROP per MA & $174^{\mathrm{a}}$ & 0.32527 & 0.209088 & 0.000 & 1.000 \\
\hline
\end{tabular}

Table 2: Descriptive Statistics of PROP per Financial Statement

An in-depth examination of PROP collected allows us to explain more clearly the types of misfit that occurred. As shown in Table 3, there is a clear prevalence of mean values for Firm Specific and New Tag items. The statistics of PROP per type and financial statement (Table 4) confirm this evidence. Moreover, Memorandum Accounts again have the highest values of misfit.

\begin{tabular}{|l|r|r|r|r|}
\cline { 2 - 5 } \multicolumn{1}{c|}{} & \multicolumn{1}{c|}{ Mean } & Std. Deviation & \multicolumn{1}{c|}{ Minimum } & \multicolumn{1}{c|}{ Maximum } \\
\hline Firm Specific & 0.0299 & 0.07211 & 0.00 & 0.53 \\
Grouped & 0.0051 & 0.00652 & 0.00 & 0.03 \\
New Tag & 0.0135 & 0.02186 & 0.00 & 0.19 \\
\hline
\end{tabular}

Table 3: Descriptive Statistics of PROP per Type

In summary, as a first general approach, these results show that the reporting practices of the Italian non-listed companies seem to be more disaggregated than the Italian GAAP Taxonomy. Hence, on the basis of our framework, we have calculated our variable of interest by adding the Firm Specific items to the New Tag items. The descriptive statistics of Disaggregated PROP (Table 5) show a mean value of $4.34 \%$ per firm. Furthermore, the mean values for the Balance Sheet and the Income Statement are quite low (4.1\% and 3.30\%, respectively), whereas the Memorandum Accounts have a higher value (17.78\%).

\begin{tabular}{|l|l|r|r|r|}
\cline { 3 - 5 } \multicolumn{1}{c|}{} & Balance Sheet & $\begin{array}{r}\text { Income } \\
\text { Statement }\end{array}$ & $\begin{array}{r}\text { Memorandum } \\
\text { Accounts }\end{array}$ \\
\hline \multirow{3}{*}{ PROP } & Firm Specific & 0.0745 & 0.1250 & 0.2360 \\
\cline { 2 - 5 } & Grouped & 0.0115 & 0.0195 & 0.3054 \\
\cline { 2 - 5 } & New Tags & 0.0331 & 0.0348 & 0.3129 \\
\hline
\end{tabular}

Table 4: PROP per Type and Financial Statement (means) 


\begin{tabular}{|l|r|r|r|r|}
\cline { 2 - 5 } \multicolumn{1}{c|}{} & \multicolumn{1}{c|}{ Mean } & Std. Deviation & \multicolumn{1}{c|}{ Minimum } & \multicolumn{1}{c|}{ Maximum } \\
\hline Dis_PROP per Firm & 0.0434 & 0.07858 & 0.00 & 0.53 \\
Dis_PROP per BS & 0.0410 & 0.07166 & 0.00 & 0.45 \\
Dis_PROP per IS & 0.0330 & 0.09358 & 0.00 & 0.64 \\
Dis_PROP per MA & 0.1778 & 0.20314 & 0.00 & 0.92 \\
\hline
\end{tabular}

Table 5: Descriptive Statistics of Disaggregated PROP

At this point, we focus the analysis on the Memorandum Accounts chart. All of the descriptive statistics reveal a clear prevalence of misfit in that document, considering the degree of PROP per firm, the degree of PROP per type and the degree of Dis_PROP. Then, according to the hypothesis formulated above, the next goal is to analyze whether the level of disaggregation of information provided by the companies in that document depends on some explanatory factors. For this purpose, we have created a multiple regression model taking those factors into account as independent variables and considering the Disaggregated PROP of Memorandum Accounts as the dependent variable. The model is defined as follows:

$$
\begin{aligned}
& \text { Dis_PROPi }=\alpha+\beta 1 A U T O M O B I L E S+\beta 2 B A S I C \_R E S O U R C E S+\beta 3 C H E M I C A L S+
\end{aligned}
$$

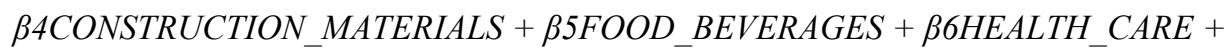

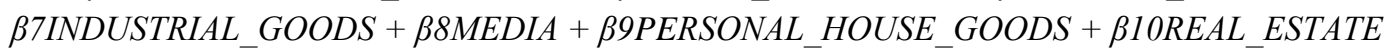

$$
\begin{aligned}
& +\beta 11 R E T A I L+\beta 12 \text { TECHNOLOGY }+\beta 13 \text { TRAVEL_LEISURE }+\beta 14 \text { UTILITIES }+\gamma \\
& L O G\left(T O T A L \_A S S E T S\right)+\pi \text { AUDIT_BIG4 }+\theta \text { Constr_PROP }+\varepsilon
\end{aligned}
$$

where:

i denotes the firms

$\beta 1$ to $\beta 14 \quad$ denote the coefficients associated with the sectors

$\gamma \quad$ denotes the coefficient associated with the size

$\pi \quad$ denotes the coefficient associated with the type of audit

$\theta$ denotes the coefficient associated with the Constricted PROP for MA 


\begin{tabular}{|c|c|c|c|c|}
\hline \multicolumn{5}{|l|}{ Dependent Variable: Dis_PROP_MA } \\
\hline \multicolumn{5}{|l|}{ Method: Least Squares } \\
\hline \multicolumn{5}{|c|}{ White Heteroskedasticity-Consistent Standard Errors \& Covariance } \\
\hline Variable & Coefficient & Std. Error & t-Statistic & Prob. \\
\hline $\mathrm{C}$ & -0.175963 & 0.136807 & -1.286217 & 0.2003 \\
\hline AUTOMOBILES & 0.062732 & 0.077481 & 0.809645 & 0.4194 \\
\hline BASIC_RESOURCES & 0.136754 & 0.071856 & 1.903165 & 0.0589 \\
\hline CHEMICALS & 0.260559 & 0.066311 & 3.929322 & 0.0001 \\
\hline CONSTRUCTION_MATERIALS & 0.041804 & 0.104342 & 0.400642 & 0.6892 \\
\hline FOOD_BEVERAGES & 0.144136 & 0.092264 & 1.562216 & 0.1203 \\
\hline HEALTH_CARE & 0.186417 & 0.093995 & 1.983259 & 0.0491 \\
\hline INDUSTRIAL_GOODS & 0.136094 & 0.072634 & 1.873704 & 0.0628 \\
\hline MEDIA & 0.079437 & 0.071209 & 1.115535 & 0.2663 \\
\hline PERSONAL_HOUSE_GOODS & 0.107814 & 0.064424 & 1.673504 & 0.0962 \\
\hline REAL_ESTATE & 0.037672 & 0.072717 & 0.518062 & 0.6051 \\
\hline RETAIL & 0.101079 & 0.064479 & 1.567631 & 0.1190 \\
\hline TECHNOLOGY & -0.050503 & 0.062547 & -0.807450 & 0.4206 \\
\hline TRAVEL_LEISURE & 0.059575 & 0.065784 & 0.905607 & 0.3665 \\
\hline UTILITIES & 0.024854 & 0.127622 & 0.194749 & 0.8458 \\
\hline LOG(TOTAL_ASSETS) & 0.032297 & 0.011788 & 2.739737 & 0.0069 \\
\hline AUDIT_BIG4 & -0.015100 & 0.045449 & -0.332246 & 0.7401 \\
\hline Constr_PROP_MA & -0.474780 & 0.073433 & -6.465444 & 0.0000 \\
\hline R-squared & 0.252478 & & & \\
\hline F-statistic & 3.099379 & & & \\
\hline Prob(F-statistic) & 0.000102 & & & \\
\hline
\end{tabular}

Table 6: Multiple regression model

The $\mathrm{R}^{2}$ value of the model indicates that the independent variables explain $25.248 \%$ of the variation of the dependent variable (see Table 6). The values of the $t$ statistic indicate that the following factors are significant: sector, size, less disaggregated information. On the basis of these results, the hypotheses stated above can be tested.

Concerning the impact of the sectors, the first hypothesis can be accepted at the 5\% significance level. Specifically, both the Chemicals and Health Care sectors have a positive and significant relationship with the dependent variable $\left(\beta_{1}=\right.$ 0.2605 and $\left.\beta_{5}=0.1864\right)$. That is, companies belonging to those sectors tend to disclose more disaggregated information than the schema provided by the regulations. The second hypothesis can also be accepted at the $1 \%$ significance level. The variable LOG(TOTAL_ASSETS) is positively associated with Disaggregated PROP $(\gamma=0.0323)$. This means that larger companies tend to report more information. The fourth hypothesis can also be accepted because the 
variable Constr_PROP_MA has a negative and significant association with the Dis_PROP $(\theta=0.4748)$. This result supports our suggestion that the practice of subdivision and addition of certain items contrasts with the practice of grouping other items in the same report. Lastly, the third hypothesis cannot be accepted; that is, the type of audit does not affect the level of disaggregation of information.

\section{DISCUSSION AND RESEARCH IMPLICATIONS.}

XBRL is becoming the leading means of global financial communication. The first area of interest, particularly, is corporate financial reporting, which must communicate, in real time, a large amount of digital financial information across the world. In this context, the role of XBRL taxonomies is fundamental because these taxonomies must reflect both the accounting principles issued by standard authorities and the current reporting practices of firms. In this study, the concept of "fit" between a standard taxonomy and financial reporting practices was examined in the context of the Italian adoption of XBRL. We have also tried to empirically identify the factors that could explain the level of misfit observed in terms of the disaggregation of information. The results obtained raise some preliminary considerations.

The first aspect concerns the dichotomy between the degrees of misfit observed among different types of financial statement. Specifically, both Balance Sheet and Income Statement have an almost perfect fit with the taxonomy, whereas the Memorandum Accounts have a consistent degree of misfit. This evidence leads us to explore this misfit in greater depth to identify the factors that can influence the different levels of disaggregation of information provided in that document. Specifically, the analysis by industries indicates that companies belonging to the Chemicals and Health Care sectors tend to disclose more information than other companies. This finding can justify some private extensions to report specific concepts pertaining to those particular sectors. Additional tests reveal that company size can also influence the information provided. Larger companies, in fact, seem to provide more disaggregated information. This result is consistent with the prevalent literature, which indicates that larger companies can provide more information for a wider number of stakeholders at relatively low costs. Lastly, it is noticed that the practice of subdivision and addition of certain items 
by some companies contrasts with the practice of grouping items by other companies.

The second aspect concerns the type of misfit observed and the differences in the aggregation of data between the reporting practices of firms and the taxonomy hierarchy. The Firm Specific and New Tag items are more prevalent than the Grouped items; that is, companies tend to report more disaggregated information. Therefore, if the firms apply the taxonomy as written without any changes, they can achieve complete comparability of data but with a loss of detailed information. In this case, the taxonomy represents a "common, agreed-upon and stable reference" (Bovee et al. 2002), but it cannot capture information at the same level of detail provided by the firms. However, if the firms prefer to extend the taxonomy by creating custom tags, they can preserve the detailed information but with a potential loss of comparability. Specifically, comparability can be preserved at least at the taxonomy hierarchical level but not for the extensions that do not represent agreed-upon concepts. Furthermore, different firms can create different tags for the same account. Unfortunately, the Italian register does not allow companies to send both the XBRL file and the extended version of their XBRL taxonomies, which is allowed in the US. This is a disincentive for companies to disclose more with XBRL; therefore these companies need to revert to the traditional PDF file to disclose more.

Furthermore, considering the general level of fit as a whole, this study suggests several broader research implications.

First, we think that a good fit between a standard taxonomy and the reporting practices of firms could facilitate the widespread adoption of XBRL. Given a well defined set of tags, the accounting departments of firms can more easily tag their data. This convenience could reduce possible skepticism towards a new technology-based method of reporting, such as XBRL, especially for small- and medium-sized entities.

Second, another advantage involves the usefulness of tagged data. When a large amount of firms rely on a unique "well fitted" standard taxonomy, a truly useful and reliable database of financial data will develop. In this way, every entity in the financial community can rely on data tagged with the same language; 
this allows them to minimize potential problems with the comparability of data.

Third, a good fit could encourage the firm to use XBRL, starting with external financial reporting and subsequently "drilling down" to internal financial and nonfinancial reporting. A possible solution could be the application of the ResourceEvent-Agent (REA) model in conjunction with the eXtensible Business Reporting Language Global Ledger (XBRL GL), as proposed by Amrhein et al. (2009). That method provides an ontology and an associated process that is able to capture a comprehensive amount of business information to be reported in XBRL format.

Lastly, a common adoption of XBRL based on a unique local standard taxonomy (such as the Italian GAAP Taxonomy for the Italian non-listed companies) could be an optimum test bed towards the possible future adoption of International Financial Reporting Standards. In other words, we believe that an early familiarization with XBRL taxonomies could help such firms in applying IFRS through a well defined international taxonomy (such as the IFRS Taxonomy $^{16}$ ).

In conclusion, we wish to restate the role of XBRL taxonomies in digital financial reporting, both for firms and for other users of financial information. Future research studies should periodically review the Italian case to detect whether and how the companies are meeting their reporting requirements through the effective application of the taxonomy. Now that the Italian XBRL adoption for non-listed companies has been outlined in this work, it will be essential to extend this research to the context of listed companies and to compare this XBRL implementation process with others at the international level, especially with the case of the SEC filing program.

\section{REFERENCES}

ADAMS, M.; HOSSAIN, M. (1998): "Managerial discretion and voluntary disclosure: empirical evidence from the New Zealand life insurance industry", Journal of Accounting and Public Policy, vol.17, n.3: 245-281. http://dx.doi.org/10.1016/S0278-4254(98)10003-0

\footnotetext{
${ }^{16}$ See http://www.ifrs.org/XBRL/IFRS+Taxonomy/Previous+taxonomies.htm
} 
AITKEN, M.; HOOPER, C.; PICKERING, J. (1997): "Determinants of voluntary disclosure of segment information: a re-examination of the role of diversification strategy", Accounting Finance, vol.37, n.1: 89-109. http://dx.doi.org/10.1111/j.1467629X.1997.tb00315.X

AMRHEIN, D.G.; FAREWELL, S.; PINSKER, R. (2009): "REA and XBRL GL: Synergies for the 21st Century Business Reporting System", The International Journal of Digital Accounting Research, vol.9, n.October: 127-152. http://dx.doi.org/10.4192/15778517-v9_5

ARMENIC, J.; MAIOCCO, M. (1981): "Improvement in disclosure by Canadian public companies", Cost and Management, vol.55, n.6: 16-20.

BALDWIN, A.A.; BROWN, C.E.; TRINKLE, B.S. (2006): "XBRL: An Impacts framework and Research Challenge", Journal of Emerging Technologies in Accounting, vol.3, n.1: 97-116. http://dx.doi.org/10.2308/jeta.2006.3.1.97

BAZLEY, M.; BROWN, P.; IZAN, H.Y. (1985): "An analysis of lease disclosures by Australian companies", Abacus, vol.21, n.1: 44-63. http://dx.doi.org/10.1111/j.14676281.1985.tb00111.x

BONSÓN, E. (2001): "The Role of XBRL in Europe", The International Journal of Digital Accounting Research, vol.1, n.December: 101-110. http://dx.doi.org/10.4192/157 7-8517-v1_5

BONSÓN, E.; CORTIJO, V.; ESCOBAR, T. (2009a): "Towards the global adoption of XBRL using International Financial Reporting Standards (IFRS)", International Journal of Accounting Information Systems, vol.10, n.1: 46-60. http://dx.doi.org/10.1016/j.accinf. $\underline{2008.10 .002}$

BONSÓN, E.; CORTIJO, V.; ESCOBAR, T. (2009b): "A Delphi Investigation to Explain the Voluntary Adoption of XBRL", The International Journal of Digital Accounting Research, vol.9, n.December: 193-205. http://dx.doi.org/10.4192/1577-8517-v9_7

BONSÓN, E.; ESCOBAR, T.; FLORES, F. (2009c): "Towards an ontology-based network for banking supervision", Online Information Review, vol.33, n.5: 943-955. http://dx.doi.org/10.1108/14684520911001927

BONSÓN, E.; ESCOBAR, T. (2006): "Digital reporting in Eastern Europe: an empirical study", International Journal of Accounting Information Systems, vol.7, n.4: 299-318. http://dx.doi.org/10.1016/j.accinf.2006.09.001

BONSÓN, E.; ESCOBAR, T. (2002): "A Survey on Voluntary Disclosure on the Internet. Empirical Evidence from 300 European Union Companies", The International Journal of Digital Accounting Research, vol.2, n.June: 27-51. http://dx.doi.org/10.4192/1577-8517-v2 2

BORITZ, J.E.; NO, W.G. (2009): "Assurance on XBRL-related documents: the case of United Technologies Corporation", Journal of Information Systems, vol.23, n.2: 49-78. http://dx.doi.org/10.2308/jis.2009.23.2.49 
BORITZ, J.E.; NO, W.G. (2008): "The SEC's XBRL Voluntary Filing Program on EDGAR: A Case for Quality Assurance", Current Issues in Auditing, vol.2, n.2: A36A50. http://dx.doi.org/10.2308/ciia.2008.2.2.A36

BORITZ, J.E.; NO, W.G. (2003): Assurance Reporting for XBRL: XARL (eXtensible Assurance Reporting Language). Trust and Data Assurances in Capital Markets: The Role of Technology Solutions. Bryant College: 17-31. http://www.xbrleducation.com/pub s/PWC_Book.pdf

BOVEE, M.; ETTREDGE, M.; SRIVASTAVA, R.P.; VASARHELYI, M.A. (2002): "Does the year 2000 XBRL Taxonomy accomodate current business financial reporting practice?", Journal of Information Systems, vol.16, n.2: 165-182.

BOVEE, M.; KOGAN, A.; SRIVASTAVA, R.P.; VASARHELYI, M.A.; NELSON, K. (2005): "Financial Reporting and Auditing Agent with Net Knowledge (FRAANK) and eXtensible Business Reporting Language (XBRL)", Journal of Information Systems, vol.19, n.1: 19-41.

CAMFFERMAN, K.; COOKE, T. (2002): "An analysis of disclosure in annual reports of U.K. and Dutch companies", Journal of International Accounting Research, vol.1, n.1: 330. http://dx.doi.org/10.2308/jiar.2002.1.1.3

CHANG, C.; JARVENPAA, S. (2005): "Pace of Information Systems Standards Development and Implementation: The Case of XBRL", Electronic Markets, vol.15, n.4: 365 - 377. http://dx.doi.org/10.1080/10196780500303029

CHOW, C.W.; WONG-BOREN, A. (1987): "Voluntary financial disclosure by Mexican corporations", The Accounting Review, vol.62, n.3: 533-541.

COHEN, E.E.; LAMBERTON, B.; ROOHANI, S. (2003): The Implications of Economic Theories for Data Level Assurances: Research Opportunities. Trust and Data Assurances in Capital Markets: The Role of Technology Solutions. Bryant College: 51-62.

CRAVEN, B.M.; MARSTON, C.L. (1999): "Financial reporting on the Internet by leading UK companies", European Accounting Review, vol.8, n.2: 321-333. http://dx.doi.org/10.1080/096381899336069

CRAVEN, B.M.; OTSMANI, B. (1999): Social environmental reporting on the Internet by leading UK companies. Paper presented at the 22nd Annual Congress of the European Accounting Association. France.

DEBRECENY, R.S.; CHANDRA, A.; CHEH, J.J.; GUITHUES-AMRHEIN, D.; HANNON, N.J.; HUTCHISON, P.D.; JANVRIN, D.; JONES, R.A.; LAMBERTON, B.; LYMER, A.; MASCHA, M.; NEHMER, R.; ROOHANI, S.; SRIVASTAVA, R.P.; TRABELSI, S.; TRIBUNELLA, T.; TRITES, G.; VASARHELYI, M.A. (2005): "Financial Reporting in XBRL on the SEC's EDGAR System: A Critique and Evaluation", Journal of Information Systems, vol.19, n.2: 191-210. http://dx.doi.org/10.23 08/jis.2005.19.2.191 
DEBRECENY, R.; FAREWELL, S.; PIECHOCKI, M.; FELDEN, C.; GRÄNING, A. (2010): "Does it add up? Early evidence on the data quality of XBRL filings to the SEC", Journal of Accounting and Public Policy, vol.29, n.3: 296-306. http://dx.doi.org/10.1016/ j.jaccpubpol.2010.04.001

DEBRECENY, R.; GRAY, G.L. (2001): "The production and use of semantically rich accounting reports on the Internet: XML and XBRL", International Journal of Accounting Information Systems, vol.2, n.1: 47-74. http://dx.doi.org/10.1016/S14670895(00)00012-9

EFENDI, J.; SMITH, M.L.; WONG, J. (2009): "Longitudinal Analysis of Voluntary Adoption of XBRL on Financial Reporting". Available at http://ssrn.com/abstract=1440956

FASB (1980): Quality Characteristics of Accounting Information. Statement of Financial Accounting Concepts No. 2. Financial Accounting Standard Board, Stamford.

GHANI, E.K.; LASWAD, F.; TOOLEY, S. (2009): "Digital Reporting Formats: Users' Perceptions, Preferences and Performances", The International Journal of Digital Accounting Research, vol.9, n.July: 45-98. http://dx.doi.org/10.4192/1577-8517-v9_3

LANG, M.; LUNDHOLM, R. (1993): "Cross-sectional determinants of analyst ratings of corporate disclosures", Journal of Accounting Research, vol.31, n.2: 246-272.

LOCKE, J.; LOWE, A. (2007): "XBRL: An (Open) Source of Enlightenment or Disillusion?", European Accounting Review, vol.16, n.3: 585-623. http://dx.doi.org/10.10 $\underline{\text { 80/09638180701507163 }}$

LYMER, A.; DEBRECENY, R. (2003): "The Auditor and Corporate Reporting on the Internet: Challenges and Institutional Responses", International Journal of Auditing, vol.7: 103-120. http://dx.doi.org/10.1111/1099-1123.00063

MARSHALL, B.; MORTENSON, K.; BOURNE, A.; PRICE, K. (2010): "Visualizing Basic Accounting Flows: Does XBRL + Model + Animation = Understanding?", The International Journal of Digital Accounting Research, vol.10, n.March: 27-54. http://dx.doi.org/10.4192/1577-8517-v10_2

MCKINNON, J.L.; DALIMUNTHE, L. (1993): "Voluntary disclosure of segment information by Australian diversified companies", Accounting Finance, vol.33, n.1: 3351. http://dx.doi.org/10.1111/j.1467-629X.1993.tb00192.x

PLUMLEE, R.D.; PLUMLEE, M.A. (2008): "Assurance on XBRL for Financial Reporting", Accounting Horizons, vol.22, n.3: 353-368. http://dx.doi.org/10.2308/acch.20 $\underline{08.22 .3 .353}$

ROOHANI, S.; XIANMING, Z.; CAPOZZOLI, E.A.; LAMBERTON, B. (2010): "Analysis of XBRL Literature: A Decade of Progress and Puzzle", The International Journal of Digital Accounting Research, vol.10, n.November: 131-147. http://dx.doi.org/10.4192/1577-8517-v10 6 
SRIVASTAVA, R.P.; KOGAN, A. (2009): "Assurance on XBRL Instance Document: A Conceptual Framework of Assertions". http://ssrn.com/abstract=1289467

WAGENHOFER, A. (2003): "Economic Consequences of Internet Financial Reporting", Schmalenbach Business Review, vol.55, n.4: 262-279.

WALLACE, R.S.O.; NASER, K. (1995): "Firm-specific determinants of the comprehensiveness of mandatory disclosure in the corporate annual reports of firms listed on the stock exchange of Hong Kong", Journal of Accounting and Public Policy, vol.14, n.4: 311-368. http://dx.doi.org/10.1016/0278-4254(95)00042-9

WALLACE, R.S.O.; NASER, K.; MORA, A. (1994): "The relationship between the comprehensiveness of corporate annual reports and firm characteristics in Spain", Accounting Business Review, vol.25, n.97: 41-53. 